\title{
Comparison of ECMWF analyses with GPS radio occultations from CHAMP
}

\author{
T. Schmidt ${ }^{1}$, J. Wickert ${ }^{1}$, S. Heise ${ }^{1}$, F. Flechtner ${ }^{1}$, E. Fagiolini ${ }^{2}$, G. Schwarz ${ }^{2}$, L. Zenner ${ }^{3}$, and T. Gruber ${ }^{3}$ \\ ${ }^{1}$ Helmholtz Centre Potsdam, GFZ German Research Centre for Geosciences, Telegrafenberg A17, 14473 Potsdam, Germany \\ ${ }^{2}$ Deutsches Zentrum für Luft- und Raumfahrt, Münchener Straße 20, 82234 Weßling, Germany \\ ${ }^{3}$ Technische Universität München, Arcisstraße 21, 80333 München, Germany
}

Received: 20 May 2008 - Revised: 23 July 2008 - Accepted: 27 August 2008 - Published: 21 October 2008

\begin{abstract}
A climatological validation of the 6-hourly operational ECMWF troposphere and lower stratosphere temperatures as well as geopotential heights between 1000 and $10 \mathrm{hPa}$ is performed using the 2001-2007 (80 months from May 2001 to December 2007) CHAMP radio occultation data. Generally there is a good agreement between ECMWF and CHAMP temperatures averaged over $300-10 \mathrm{hPa}$ for all years/seasons with global annual mean biases (standard deviations) less than 0.3 (1.7) K. Regional and temporal discrepancies occur within the polar vortex mainly on the Southern Hemisphere and the tropical tropopause region. Global annual mean biases (standard deviations) of geopotential heights between 300 and $10 \mathrm{hPa}$ are in the range of -30 up to $+5(30-50)$ geopotential meter. Larger deviations from the mean values are also observed in the tropics and polar zones. Both, the biases and standard deviations between CHAMP and ECMWF temperatures and geopotential heights differ significantly before and after February and December 2006, i.e. the dates when ECMWF increased the number of model levels from L60 to L91 (1 February 2006) and where ECMWF became one of the first weather centers assimilating radio occultation data (since 12 December 2006), mainly from the COSMIC mission. At ECMWF the CHAMP data were only assimilated until 4 February 2007, e.g. both data sets are mostly independent from each other during the time period considered here.
\end{abstract}

Keywords. Meteorology and atmospheric dynamics (Climatology; Middle atmosphere dynamics; Instruments and techniques)

Correspondence to: T. Schmidt

(tschmidt@gfz-potsdam.de)

\section{Introduction}

The European Centre for Medium-Range Weather Forecasts (ECMWF) operational analyses from the Integrated Forecasting System (ECMWF, 2007a) are widely used for several applications in atmospheric research. Additionally, the daily 6-hourly analyses are also applied in adjacent fields needing information about the global atmospheric state on different time scales.

For example, a remaining problem for the GRACE (Gravity Recovery And Climate Experiment) gravity field analysis is the de-aliasing of short-term non-tidal atmospheric and oceanic mass variations (Tapley et al., 2004; Flechtner et al., 2006). For computation of the atmospheric contribution and for forcing of the used ocean model various parameters from an atmospheric weather model, such as surface pressure, geopotential height (GPH), and temperature and humidity at different vertical levels, are applied. These atmospheric parameters are assumed to be error free. Any departure from this assumption leads to aliasing and misinterpretation of the resulting gravity field. Therefore, for all atmospheric parameters realistic error characterizations should be established.

The current atmospheric model for the GRACE gravity field analysis is the ECMWF operational model. One way to develop error measures is to compare the ECMWF model with other data bases, e.g. from the National Center for Environmental Prediction (NCEP) or with independent global atmospheric data sets.

In this contribution we compare the ECMWF multi-level temperature and GPH data with GPS radio occultation (RO) data from CHAMP (CHAllenging Minisatellite Payload) for the time period 2001-2007, which represents the first longterm GPS RO data set (Wickert et al., 2005, 2001). The RO technique uses GPS radio signals received aboard low Earth orbiting satellites for atmospheric limb sounding. Global atmospheric temperature profiles are derived with high vertical

Published by Copernicus Publications on behalf of the European Geosciences Union. 


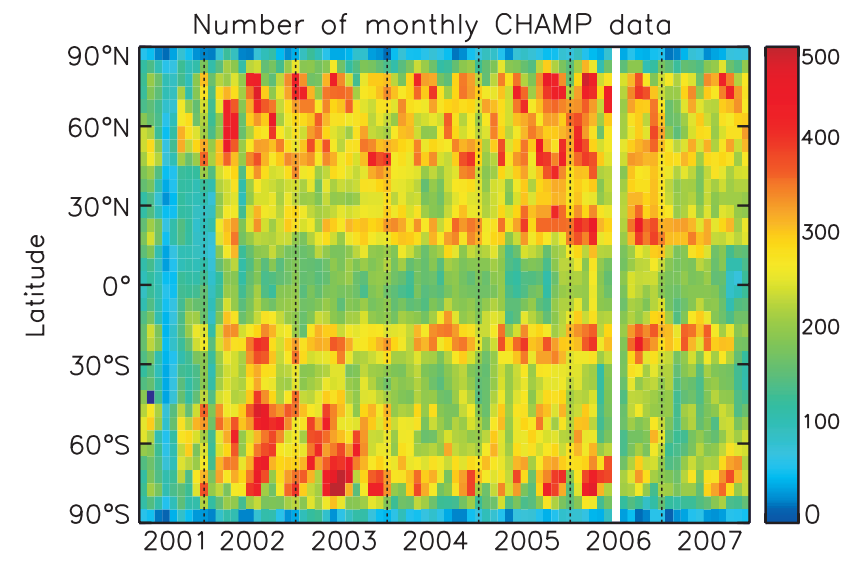

Fig. 1. Zonal monthly mean number of GPS RO CHAMP data from May 2001-December 2007.

resolution (Kursinski et al., 1997; Rocken et al., 1997; Melbourne et al., 1994). Mean biases and standard deviations (stddev) of the compared parameters will be shown and discussed.

Careful attention is given to the fact that the ECMWF assimilation scheme has experienced two important changes during the time period considered here: First, the number of vertical model levels was increased from L60 to L91 in February 2006 (ECMWF, 2006). Second, ECMWF became one of the first weather centers (since 12 December 2006) assimilating GPS RO data (Healy et al., 2007; Healy, 2007; ECMWF, 2007b; Bormann and Healy, 2005), mainly from the US-Taiwanese COSMIC (Constellation Observing System for Meteorology, Ionosphere, and Climate) mission (Anthes et al., 2008). CHAMP data were assimilated at ECMWF only until 4 February 2007 (S. Healy, ECMWF, personal communication, 2008), i.e. with the exception of the time interval between 12 December 2006 and 4 February 2007 (55 days) the ECMWF and CHAMP data sets used here can be considered independent from each other. Changes in mean biases and stddev between the pre- and post-assimilation periods will be pointed out.

Nevertheless, the most important parameter for GRACE de-aliasing is the surface pressure, which does not change significantly by these changes in the assimilation scheme.

In the past, several comparison studies between GPS RO data and radiosondes as well as cross-validations with other satellite sensors have already been performed (e.g. Steiner et al., 2007; Gobiet et al., 2007; Wickert, 2004a; Wang et al., 2004; Hajj et al., 2004). Special comparisons of tropopause parameters between CHAMP and ECMWF can be found in, e.g. Borsche et al. (2007) and Schmidt et al. (2006, 2005a, 2004).

For a climatological validation of stratospheric temperatures between ECMWF and CHAMP for 2001-2004, see Gobiet et al. (2005). This is the most comprehensive val- idation study between ECMWF and CHAMP RO data in the altitude range from $10-30 \mathrm{~km}$. Most of the results are confirmed by our study, but due to the essential changes in the ECMWF assimilation scheme in February and December 2006 also differences are now detected. We also extend our study by additional comparisons of GPHs.

The paper is organized as follows: Sect. 2 describes the data processing and validation methodology including the derivation of vertical atmospheric parameters from CHAMP. In Sect. 3 we discuss the results according to the complete time interval considered here, the latitude-time section of mean biases and stddevs, and seasonal variations. At the end a summary and conclusions follow.

\section{Data processing and validation methodology}

\subsection{CHAMP data processing}

\subsubsection{Deriving atmospheric parameters}

A detailed general description to derive vertical atmospheric profiles from RO measurements is presented by Melbourne et al. (1994) or Kursinski et al. (1997); specifications for the CHAMP RO data can be found in Wickert et al. (2005) or Hajj et al. (2004). Here, we give a brief summary: The Black-Jack GPS receiver onboard CHAMP records phase and amplitude variations with high temporal resolution $(50 \mathrm{~Hz})$ during an occultation event. By using high precision orbit information from CHAMP and the occulting GPS satellites (König et al., 2005) the atmospheric excess phase can be extracted which is related to a bending angle profile. Assuming spherical symmetry the bending angles can be related to the refractive index $n$. Finally, the atmospheric refractivity $N$ is given by (Smith and Weintraub, 1953):

$N=(n-1) \cdot 10^{6}=77.6 \frac{p}{T}+3.73 \cdot 10^{5} \frac{e_{w}}{T^{2}}$

(with $p$ : total air pressure, $T$ : air temperature, and $e_{w}$ : water vapor pressure). $N$ is the basic meteorological observable determined by the GPS RO technique.

To convert the refractivity profiles into pressure and temperature profiles the assumption of dry air has to be made because of the ambiguity between the dry and wet part in the resulting refractivity profile (Eq. 1). Further on, by applying the hydrostatic equation pressure and temperature profiles can be calculated. In the current retrieval version 005 (Wickert et al., 2004b) ECMWF pressure at $43 \mathrm{~km}$ is used for the initialization of the pressure profile. This is one atmospheric scale height above the upper level for which profile data are provided $(35 \mathrm{~km})$.

Since the saturation water vapor pressure decreases with decreasing temperature, water vapor in the troposphere can be ignored if the temperature is below $250 \mathrm{~K}$ (Kursinski et al., 1997). In our study we follow Leroy (1997) and apply 


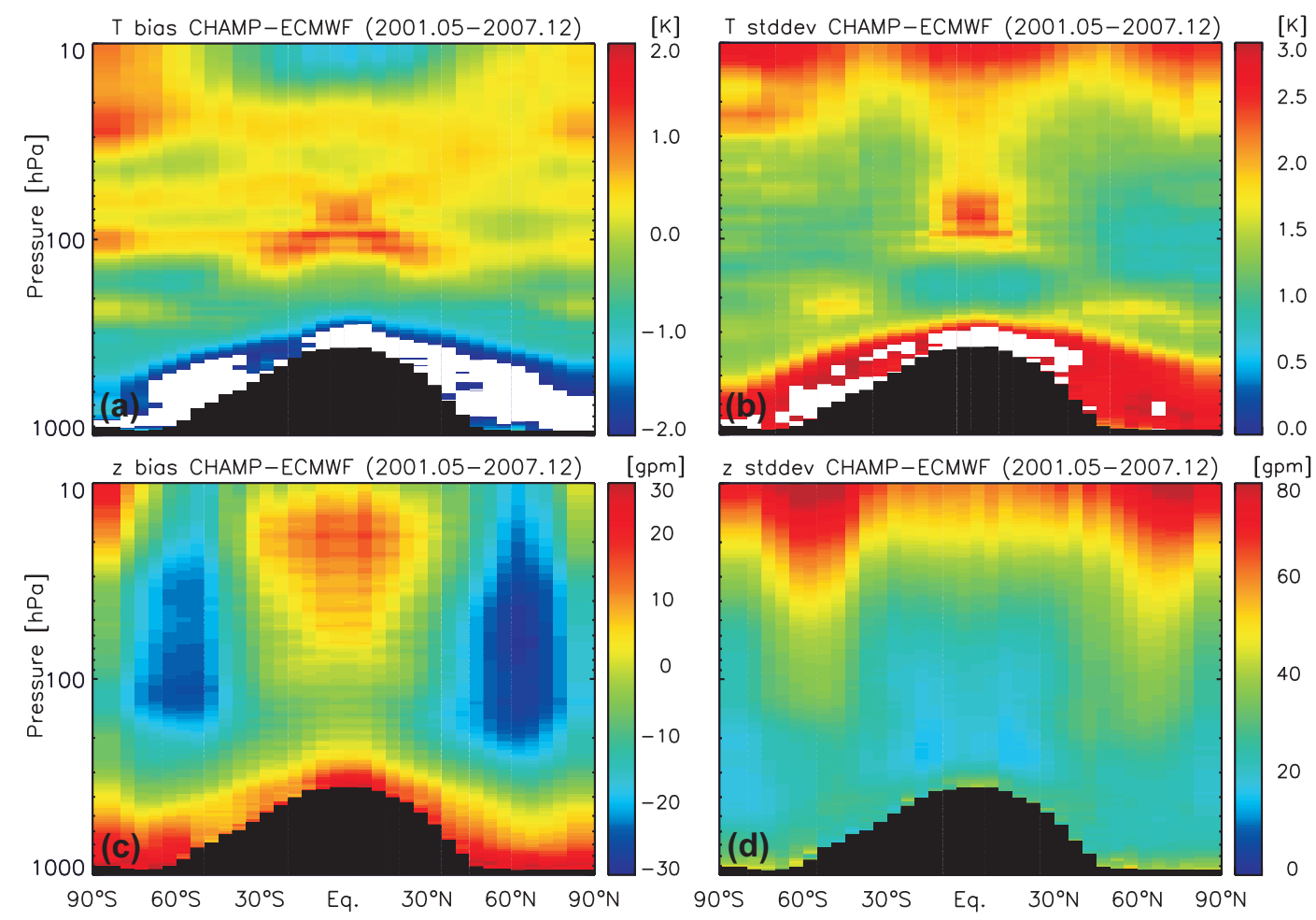

Fig. 2. Zonal mean temperature bias (a), temperature stddev (b), GPH bias (c) and GPH stddev between CHAMP and ECMWF for the pressure (altitude) range 1000-10 hPa and the time interval May 2001-December 2007. The meridional resolution is $5^{\circ}$ between $77.5^{\circ} \mathrm{N}-$ $77.5^{\circ} \mathrm{S}$ and $10^{\circ}$ for $85^{\circ} \mathrm{N}$ and $85^{\circ} \mathrm{S}$. The vertical pressure resolution corresponds to an altitude resolution of about $200-300 \mathrm{~m}$. The black areas denote regions with temperatures above $250 \mathrm{~K}$. In the white areas the bias is less than $-2 \mathrm{~K}$ (a) and the stddev is larger than $3 \mathrm{~K}$ (b).

this criterion, i.e. we compared CHAMP and ECMWF temperatures as well as GPHs only if the temperature of both data sets was below $250 \mathrm{~K}$.

\subsubsection{Vertical resolution}

The vertical resolution of an occultation measurement is determined by the contribution of individual atmospheric layers to net bending along the ray path. As discussed in Kursinski et al. (1997) by using the geometrical optics approach the vertical resolution is limited by the diameter of the first Fresnel zone $z_{F}$. For the CHAMP orbit geometry $z_{F}$ is about $1.4 \mathrm{~km}$ in the stratosphere (about $270 \mathrm{~km}$ horizontal resolution). Because of the exponential increase of the refractivity towards the Earth's surface $z_{F}$ decreases to about $0.5 \mathrm{~km}$ (horizontal resolution about $80 \mathrm{~km}$ ).

Considering diffraction effects and applying wave optical methods for the data analysis as, e.g. the Full Spectrum Inversion (FSI) method (Jensen et al., 2003) the vertical resolution can be improved significantly (to about $50 \mathrm{~m}$ ).

In our current software version (005) we have implemented both, the geometrical optics approach for heights above $15 \mathrm{~km}$ and the FSI method for heights below $10 \mathrm{~km}$. In the transition zone from $10-15 \mathrm{~km}$ a combination of both is used. This results in a physical vertical resolution of about $1 \mathrm{~km}$ above $15 \mathrm{~km}$ altitude and a vertical resolution less than $1 \mathrm{~km}$ below. For data provision all data were interpolated between the lowest level and $35 \mathrm{~km}$ with a vertical step width of $200 \mathrm{~m}$.

\subsection{The data base}

CHAMP delivers continuously between 150-200 temperature profiles daily (Wickert et al., 2005; Schmidt et al., 2005b) since May 2001. Thus, the CHAMP mission generates the first long-term GPS RO data set. Figure 1 shows the zonal monthly mean number of CHAMP data for the time interval May 2001-December 2007 (more than 439000 temperature profiles).

In the monthly time series one month was rejected completely if only data from less than $50 \%$ of the days per month were available. This exclusion criteria was fulfilled for July 2006 only.

\subsection{Validation methodology}

For the validation of ECMWF temperature and GPHs, differences (bias) and stddevs with CHAMP were determined. The ECMWF temperature profiles were obtained by interpolating 

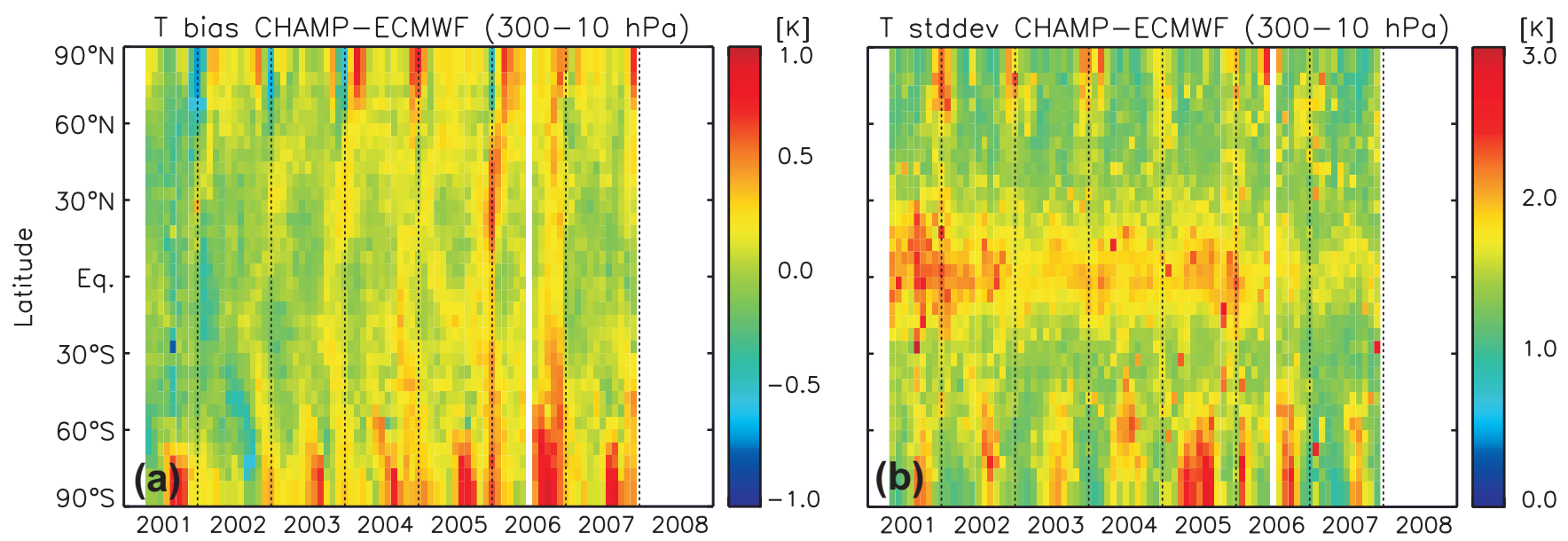

Fig. 3. Zonal monthly mean temperature bias (a) and stddev (b) between CHAMP and ECMWF averaged over the pressure (altitude) range $300-10 \mathrm{hPa}$. The meridional resolution is $5^{\circ}$ between $77.5^{\circ} \mathrm{N}-77.5^{\circ} \mathrm{S}$ and $10^{\circ}$ for $85^{\circ} \mathrm{N}$ and $85^{\circ} \mathrm{S}$ (34 latitude bands).

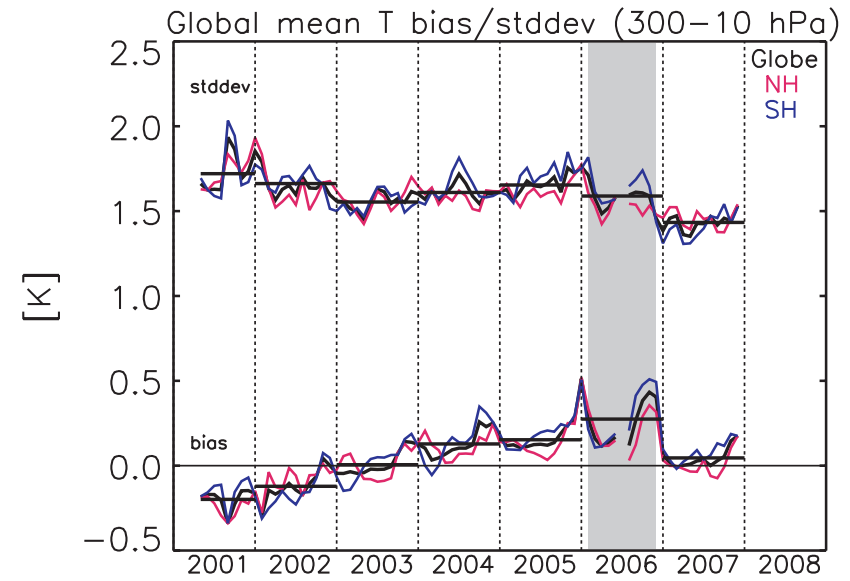

Fig. 4. Global, northern hemispheric and southern hemispheric monthly mean temperature bias and stddev between CHAMP and ECMWF for the pressure (altitude) range 300-10 hPa. The left side of the shaded area denote the month when the ECMWF model levels have increased from 60 to 91 (February 2006), the right side of the shaded area corresponds to the beginning of the assimilation of GPS RO data at ECMWF (December 2006). The yearly horizontal lines denote the annual mean of the bias and stddev, respectively.

the 6-hourly operational ECMWF data sets to the time of the occultation event, whereas the ECMWF temperature fields are extracted on all model levels (T511/L60 until 1 February 2006 and T799/L91 after) with a reduced horizontal resolution of about $0.56^{\circ}$ in latitude and longitude (T319). All changes in the ECMWF analysis and forecasting system since 1985 are available at www.ecmwf.int/products/data/ operational_system/evolution.

Because the CHAMP and ECMWF profiles are not available at the same altitude or pressure levels, the comparison of temperature and GPH data were performed on 153 constant pressure levels beween 1000 and $10 \mathrm{hPa}$, representing approximately a vertical resolution of $200-300 \mathrm{~m}$. For this reason each individual CHAMP and ECMWF profile was interpolated to these pressure levels and temperature/GPH differences were determined if both, the CHAMP and ECMWF temperature was below $250 \mathrm{~K}$ (see above for this criterion).

The determination of systematic biases and stddevs requires the analysis of differences between CHAMP and ECMWF profiles. It has to be noted, however, that both types of profiles are characterized by slightly different vertical resolutions. Following good practice, we should adapt the resolutions prior to taking the differences. This, however, requires the availability of correct averaging kernels as discussed by Rodgers (2000). As no validated averaging kernels of the CHAMP retrieval were available to us, we had to limit ourselves to a direct differencing.

For statistical evaluation monthly zonal biases/stddevs are calculated at the selected pressure levels. The zonal bins were divided into $5^{\circ}$ latitude bands centered at $77.5^{\circ} \mathrm{N}$, $72.5^{\circ} \mathrm{N}, 67.5^{\circ} \mathrm{N}, \ldots, 67.5^{\circ} \mathrm{S}, 72.5^{\circ} \mathrm{S}, 77.5^{\circ} \mathrm{S}$ (32 latitude bands). Due to the poorer monthly data coverage at the poles (Fig. 1) two $10^{\circ}$ latitude bands centered at $85^{\circ} \mathrm{N}$ and $85^{\circ} \mathrm{S}$ were used leading to a total of 34 latitudes bands.

\section{Results}

\subsection{The complete data set analysis}

\subsubsection{Temperature}

Figure 2 gives an overview of the zonal temperature and GPH biases and stddevs for the overall time interval from May 2001 to December 2007. Some general features are 

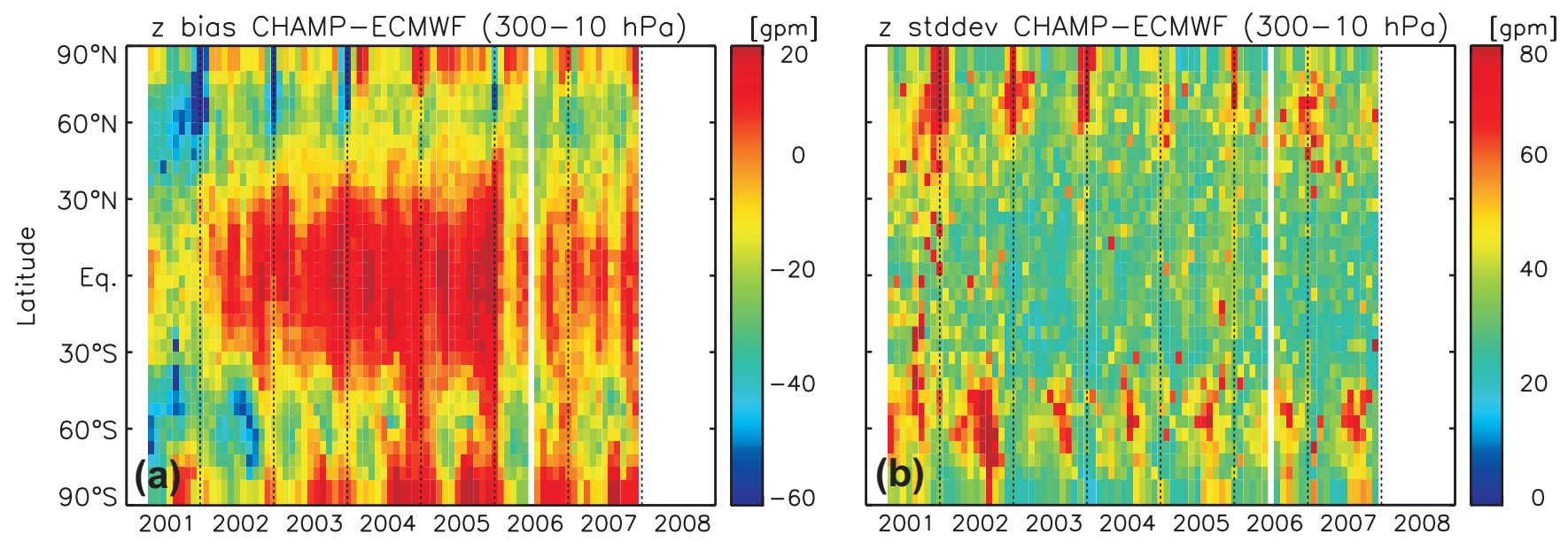

Fig. 5. Same as Fig. 3, but for the GPH.

observed: The overall temperature bias (Fig. 2a) varies generally between $\pm 1.5 \mathrm{~K}$ in the extra-tropics above $300 \mathrm{hPa}$. In the tropics $\left(30^{\circ} \mathrm{N}-30^{\circ} \mathrm{S}\right)$ the $\pm 1.5 \mathrm{~K}$ bias is reached above the $200 \mathrm{hPa}$ level.

The negative temperature bias exceeding $-2 \mathrm{~K}$ in the troposphere (white area in Fig. 2a) can be clearly addressed to the non-consideration of water vapor in the temperature retrieval (Eq. 1). Apparently, the "below $250 \mathrm{~K}$ temperature criterion" where water vapor should be negligible (Kursinski et al., 1997) seems to be questionable.

The positive temperature bias $(>1 \mathrm{~K})$ in the tropical tropopause and the adjacent regions above $(120-60 \mathrm{hPa})$ was already discussed in Gobiet et al. (2005) or Borsche et al. (2007) and is probably related to the lower vertical resolution of the ECMWF model in general. As a consequence, the possibility to dissolve gravity waves in the lower tropical stratosphere is weak compared with the CHAMP data set leading to enhanced stddevs (Fig. 2b). The stratospheric temperature bias structure in the polar regions ("stratospheric ringing", weakly implied in the overall plot) was also a topic in Gobiet et al. (2005) and will be discussed here later mainly with respect to the changes in the ECMWF assimilation scheme.

Generally, the temperature bias is larger on the Southern Hemisphere (SH) than in the Northern Hemisphere (NH) resulting from the sparse coverage of the $\mathrm{SH}$ with radiosonde observations. The appropriate mean stddev (Fig. 2b) for the time interval considered here is less than $3 \mathrm{~K}$ in the altitude ranges with temperature biases between $\pm 1.5 \mathrm{~K}$. Largest stddev values are observed above $20 \mathrm{hPa}$.

\subsubsection{Geopotential heights}

The overall bias and stddev of the GPHs between CHAMP and ECMWF are shown in Fig. 2c, d. Zonal mean values ranging between \pm 30 geopotential meter (gpm) for the bias

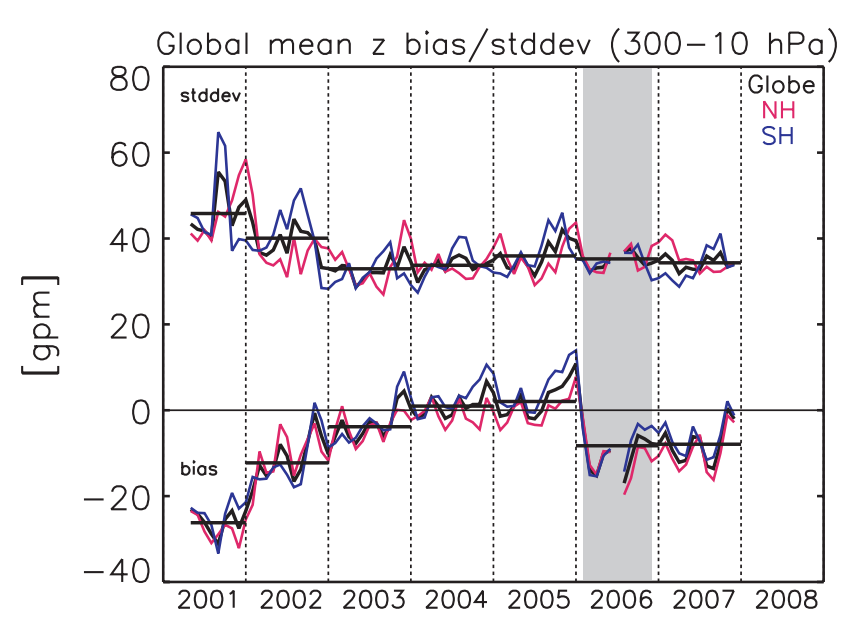

Fig. 6. Same as Fig. 4, but for the GPH.

and up to $80 \mathrm{gpm}$ for the stddev for regions with temperatures less than $250 \mathrm{~K}$.

In the tropics and subtropics $\left(40^{\circ} \mathrm{N}-40^{\circ} \mathrm{S}\right)$ on both hemispheres the mean GPH bias between $250-10 \mathrm{hPa}$ is about $\pm 15 \mathrm{gpm}$ with a mean stddev less than $50 \mathrm{gpm}$ (for the complete time interval 2001-2007).

In the mid-latitudes and polar zones both the bias and stddev increase. The pronounced lower stratospheric negative GPH bias of up to $-30 \mathrm{gpm}$ centered at $60^{\circ}$ on both hemispheres is remarkable. The SH minimum coincides with the climatological location of the relatively stable SH polar vortex, whereas the $\mathrm{NH}$ minimum is broader reflecting the much larger lower stratospheric synoptic variability between $50^{\circ} \mathrm{N}-80^{\circ} \mathrm{N}$.

Figure 2 represents the mean state between May 2001 and December 2007. The GPH bias pattern however is similar during different seasons with lowest biases during winter and 

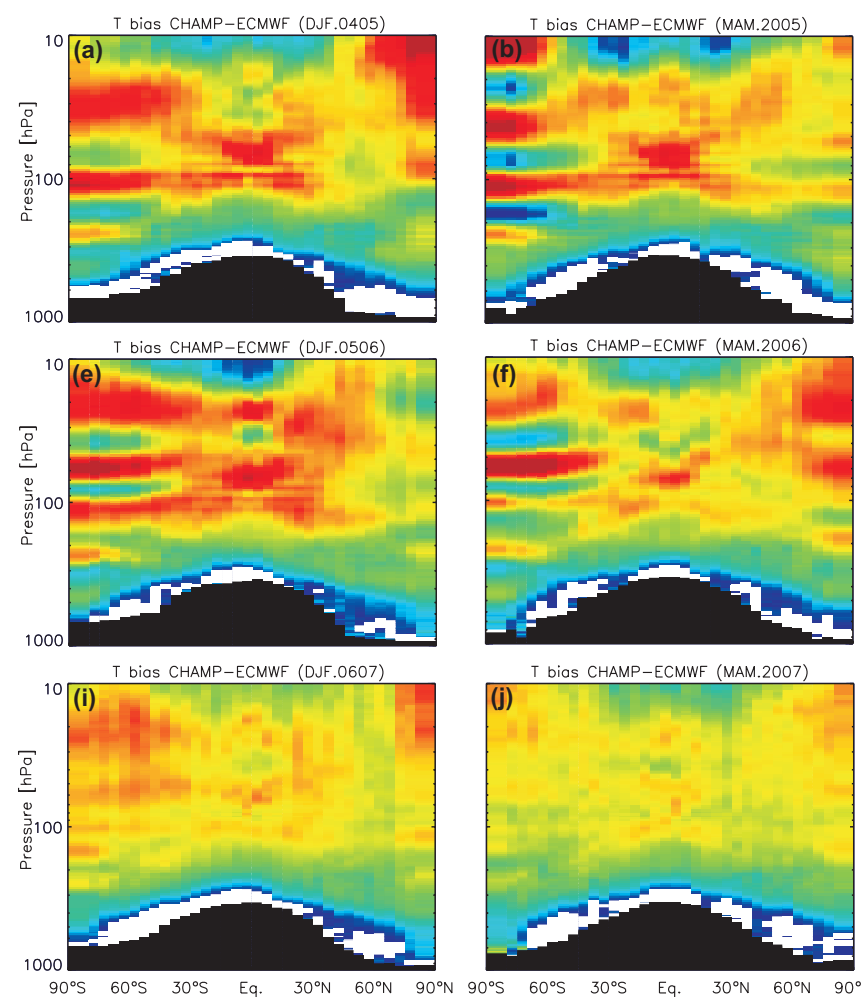

T bios CHAMP-ECMWF (MAM.2007)

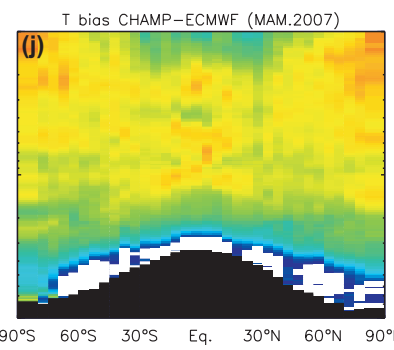

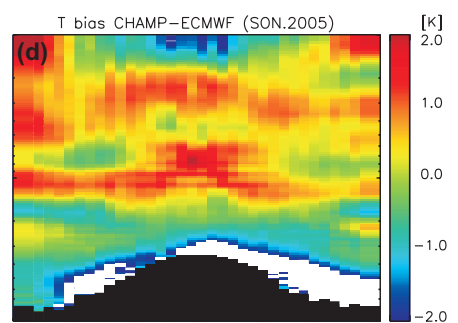

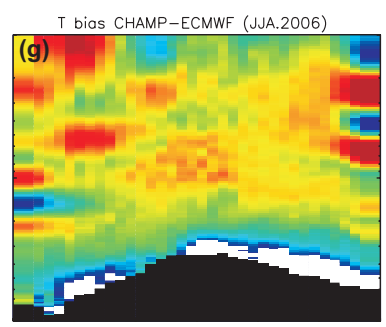

T bias CHAMP-ECMWF (JJA.2007)
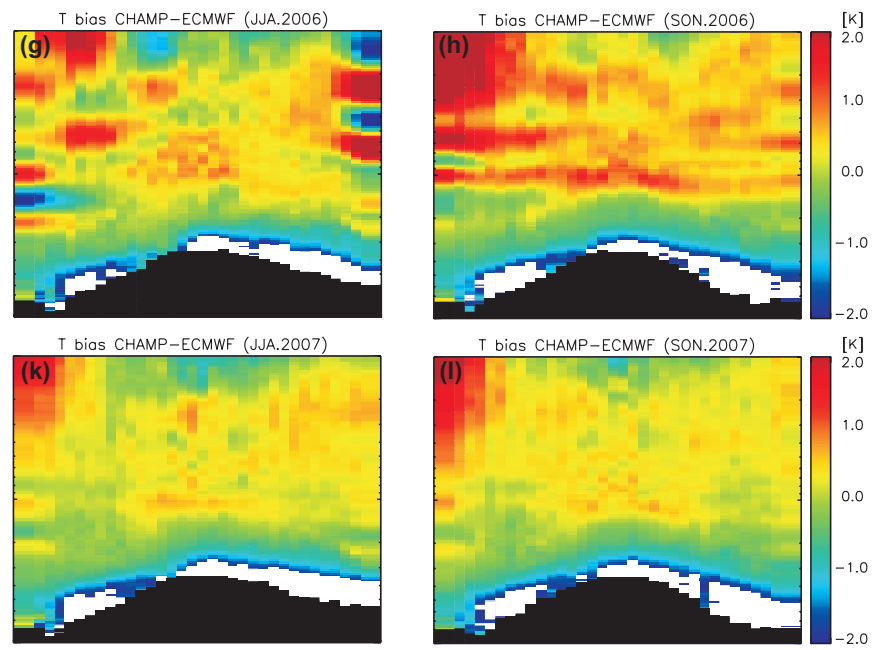

T bios CHAMP-ECMWF (SON.2007)

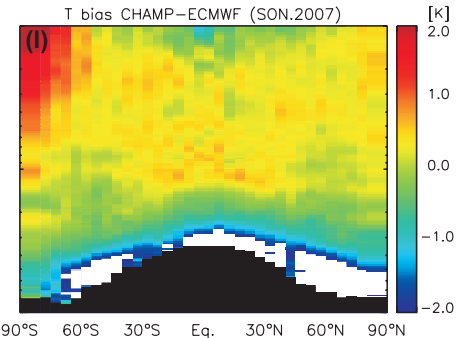

Fig. 7. Zonal mean temperature bias between CHAMP and ECMWF for the pressure (altitude) range 1000-10 hPa for different seasons (DJF.0405-SON2007). The meridional resolution is $5^{\circ}$ between $77.5^{\circ} \mathrm{N}-77.5^{\circ} \mathrm{S}$ and $10^{\circ}$ for $85^{\circ} \mathrm{N}$ and $85^{\circ} \mathrm{S}$. The vertical pressure resolution corresponds to an altitude resolution of about $200-300 \mathrm{~m}$. The black areas denote regions with temperatures above $250 \mathrm{~K}$. In the white areas the bias is less than $-2 \mathrm{~K}$.

spring whereas the positive tropical bias between $50-10 \mathrm{hPa}$ is significantly reduced after the increase of the ECMWF model levels in February 2006 (see Fig. 9).

\subsection{Time-latitude variations}

The previous section gave an overview about the mean temperature and GPH bias as well as the stddev between CHAMP and ECMWF for the complete time period considered here and could be interpreted as the mean state. In the following we go more in detail with respect to the time evolution of the temperature and GPH differences between CHAMP and ECMWF.

The possible quantities describing the goodness of the deviations between CHAMP and ECMWF here are mean temperatures and GPH biases/stddevs between $300-10 \mathrm{hPa}$. As shown in Fig. 2 the influence of water vapor can be neglected in that region even in the tropics.

\subsubsection{Temperature}

Figure 3 shows the monthly evolution of the zonal temperature bias and stddev. It can be seen that the mean bias has a maximum in the polar zones during winter/spring. The extra- tropical stddev follows the bias pattern whereas the tropical temperature stddev is also enhanced reaching values comparable to those in the polar regions.

We do not interpret all variations of the bias and stddev with respect to the changes in ECMWF assimilation scheme, but focus here on February 2006 (L60 to L91) and December 2006 (assimilation of GPS RO data).

It is already visible in Fig. 3a that apart from annual cycles the mean bias between $300-10 \mathrm{hPa}$ increases at nearly all latitudes between 2001 and 2006. In 2007 (after assimilation of RO data) the temperature bias seems to be decreased globally.

To revise this trend we defined global monthly mean temperature biases/stddevs by cosine-weighted means of the single zonal means (Fig. 4). The positive temperature bias trend until 2006 is notable. The improvement of the vertical model resolution seems to have no impact on the temperature bias, but the assimilation of RO data in late 2006. The annual temperature bias in 2007 has nearly vanished.

The annual global stddev decreases between 2001 and 2007 from about $1.7 \mathrm{~K}$ to $1.5 \mathrm{~K}$ with the largest improvement after the assimilation of RO data. 

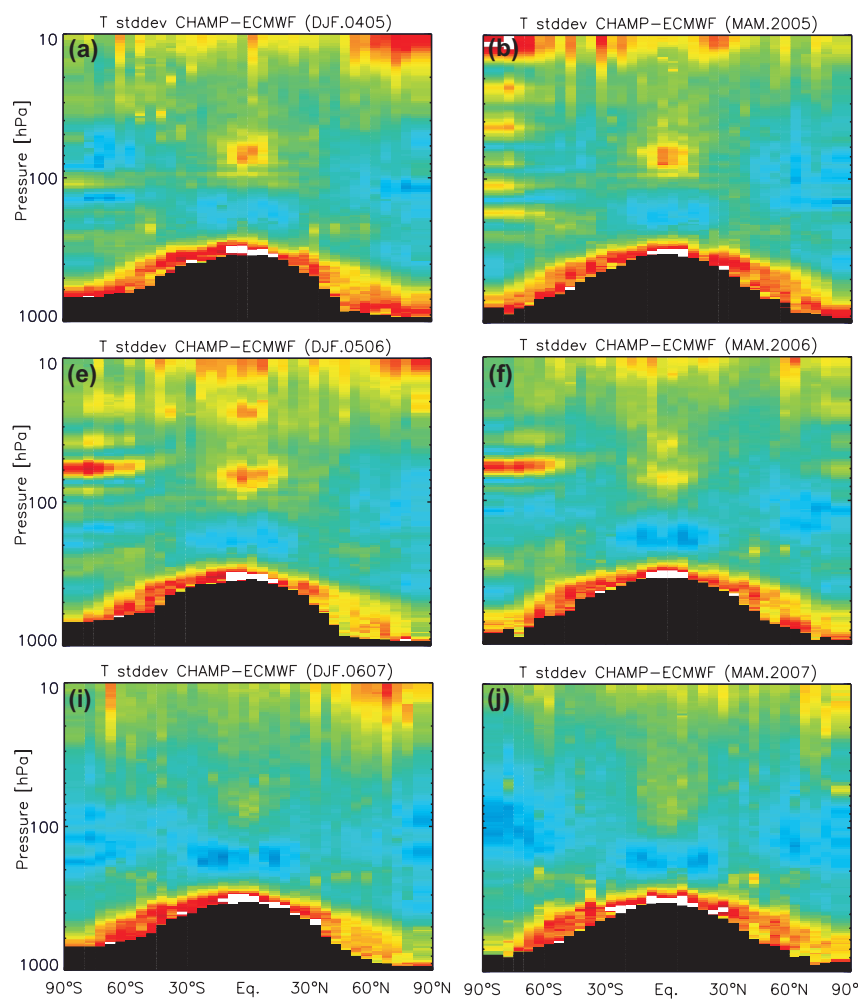

T stddev CHAMP-ECMWF (MAM.2007)

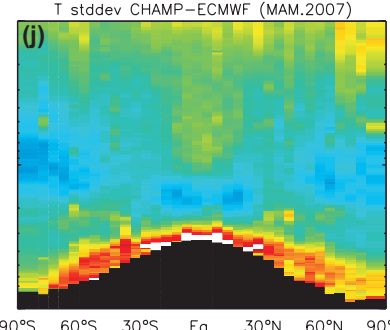

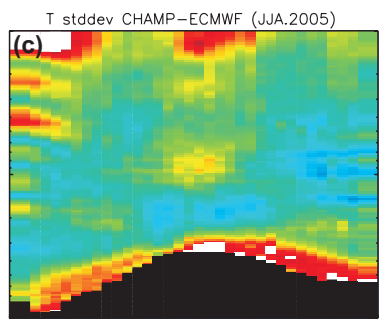

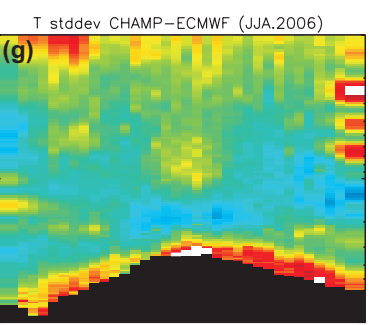

T stddev CHAMP-ECMWF (JJA.2007)

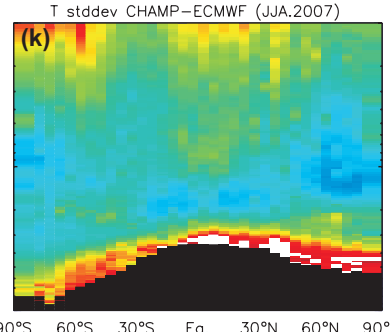

Fig. 8. Same as Fig. 7, but for the stddev. In the white areas the stddev is larger than $4 \mathrm{~K}$.

The improvements in both, the temperature bias and stddev suggest the assumption that the new RO data have assigned a considerable weight between $300-10 \mathrm{hPa}$ in the assimilation scheme.

A comparison of the $\mathrm{NH}$ and $\mathrm{SH}$ temperature biass/stddevs show differences not exceeding $0.2 \mathrm{~K}$ with slightly higher $\mathrm{SH}$ biases indicating the better spatial coverage of the $\mathrm{NH}$ with radiosondes.

\subsubsection{Geopotential heights}

The latitude-time section of the mean GPH bias and stddev between $300-10 \mathrm{hPa}$ is presented in Fig. 5. Values up to $20 \mathrm{gpm}$ are observed in the tropics from 2002-2005. During the polar vortex season on the SH similar values are reached. In the mid-latitudes on both hemispheres negative GPH biases are present with values up to -60 gpm in 2001 and 2002 .

The corresponding stddev is enhanced in the mid-latitudes and polar regions on both hemispheres with maximum values of $80 \mathrm{gpm}$ in 2001/2002 (Fig. 5b).

Figure 6 shows the temporal evolution of the global mean GPH bias and stddev between $300 \mathrm{hPa}$ and $10 \mathrm{hPa}$. There is a similar positive GPH bias trend between 2001 and 2004 as already seen in the global temperature bias (Fig. 4). During the same time period a decreased annual GPH stddev is observed from about $45 \mathrm{gpm}$ down to $35 \mathrm{gpm}$.
In contrast to the temperature bias, the GPH bias in 2006 and 2007 is degraded after the ECMWF level number increase in February 2006 compared with the three years before. From 2003-2005 the bias had nearly vanished, whereas 2006 and 2007 a slightly negative annual mean bias of about $-10 \mathrm{gpm}$ is observed. The largest difference between the mean annual temperature and GPH bias is that the latter is not affected by the assimilation of RO data.

The annual mean stddev is also not affected by the two changes in the assimilation scheme mainly considered here. The values are nearly constant since 2003 (35 gpm).

Considering differences between the hemispheres one can see that there is a slightly larger bias on the SH. The GPH stddev exhibits an annual cycle with a maximum in the appropriate winter season and a minimum during summer. The amplitude reaches nearly the same magnitude on both hemispheres during a year.

\subsection{Seasonal variations}

For a more detailed study of the far-reaching changes in the ECMWF assimilation scheme (i.e. L60 to L91 and assimilation of GPS RO data) onto the vertical structure of the CHAMP-ECMWF temperature and GPH bias/stddev, Figs. 7-9 present seasonal mean values for the years 20052007. 

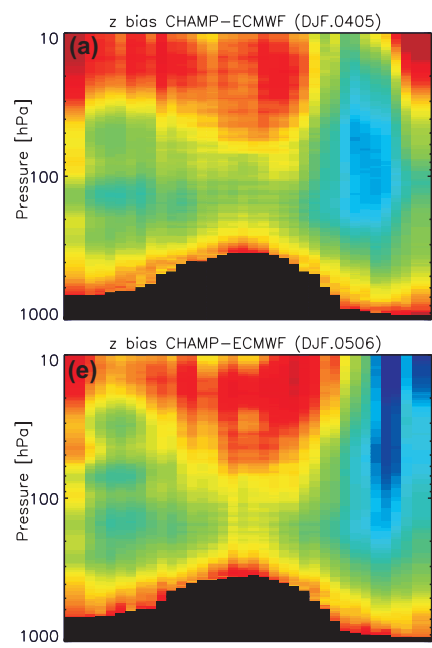

bios CHAMP-ECMWF (DJF.0607)

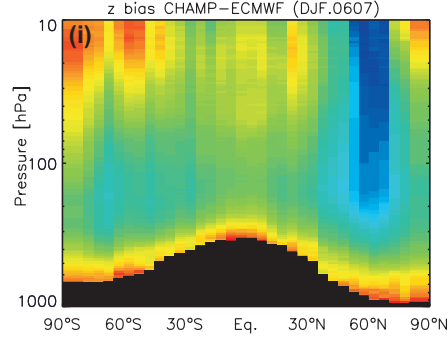

$z$ bias CHAMP-ECMWF (MAM.2005)

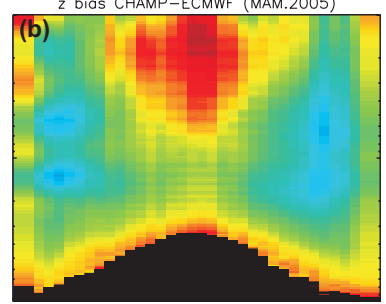

bias CHAMP-ECMWF (MAM.2006)

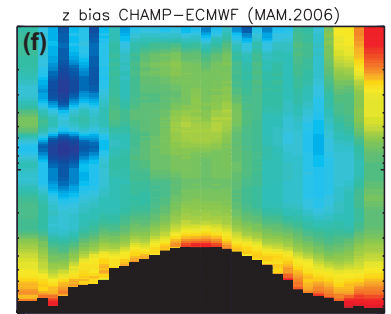

$z$ bios CHAMP-ECMWF (MAM.2007)

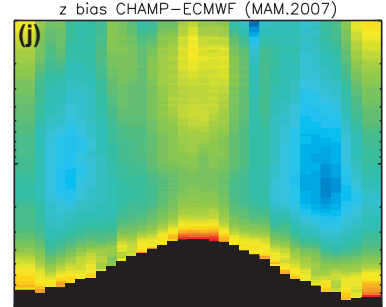

Dios CHAMP-ECMWF (JJA.2005)
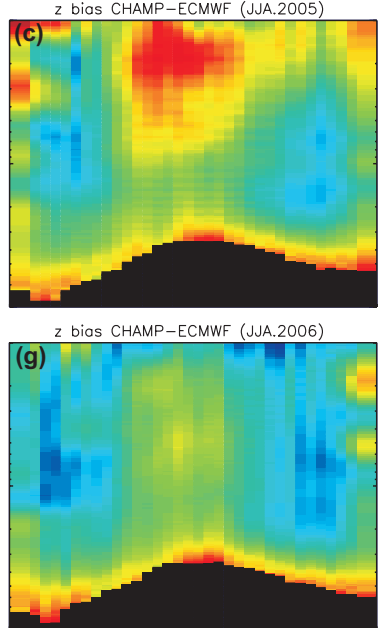

$z$ bios CHAMP-ECMWF (JJA.2007)

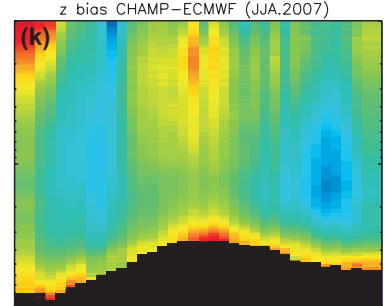

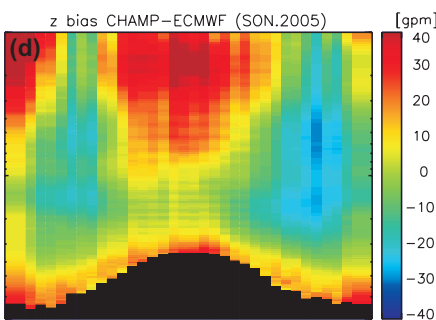

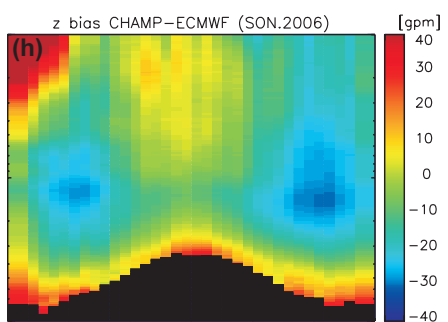

z bias CHAMP-ECMWF (SON.2007)

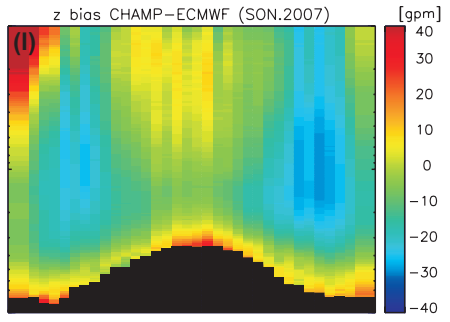

Fig. 9. Zonal mean GPH bias between CHAMP and ECMWF for the pressure (altitude) range 1000-10 hPa for different seasons (DJF.0405SON.2007). The meridional resolution is $5^{\circ}$ between $77.5^{\circ} \mathrm{N}-77.5^{\circ} \mathrm{S}$ and $10^{\circ}$ for $85^{\circ} \mathrm{N}$ and $85^{\circ} \mathrm{S}$. The vertical pressure resolution corresponds to an altitude resolution of about $200-300 \mathrm{~m}$. The black areas denote regions with temperatures above $250 \mathrm{~K}$.

The seasons were classified as follows: DecemberFebruary (DJF), March-May (MAM), June-August (JJA), and September-November (SON).

Figure 7 shows the CHAMP-ECMWF temperature bias between the seasons DJF 2004/2005 and SON 2007. Most of the bias structure observed for the complete time interval can be also found here (Fig. 2a).

The most remarkable feature in the polar lower stratosphere first described by Bormann and Healy (2005) and Gobiet et al. (2005) is the so-called "stratospheric ringing" pattern. This temperature bias structure is more or less observed in the SH polar stratosphere as well as in the northern part (Fig. 7a-h). Gobiet et al. (2005) discussed this bias in connection with the assimilation of AMSU-A radiances whose temperature weighting functions for different channels are close to the bias wave pattern. The final conclusion of Gobiet et al. (2005) is that the temperature bias can be clearly attributed to the ECMWF analysis.

Due to the inclusion of the GPS RO data in the ECMWF operational model the 'stratospheric ringing' structure disappeared (Fig. 7i-1). As already discussed in Sect. 3.2.1 (Fig. 4) there is nearly no temperature bias between CHAMP and ECMWF between $300-10 \mathrm{hPa}$ after assimilation of the RO data (Fig. 7i-1). From this we conclude that the RO data gain high priority in the ECMWF assimilation scheme.
For completion, Fig. 8 presents the seasonal temperature stddev with some of the same features as observed in the temperature bias. During the time before December 2006 also a ringing structure of the stddev can be found which has vanished afterwards.

The seasonal variation of the GPH bias between 20052007 is shown in Fig. 9. As discussed above one can clearly see the significant reduction of the positive tropical lower stratospheric bias after increase of the ECMWF model levels from L60 to L91 whereas the assimilation of RO data has nearly no effect. The negative GPH bias in the mid-latitudes and sub-polar regions is present all the time, but slightly reduced after DJF 2006/2007 (Fig. 9j-1).

\section{Summary}

In this study we have compared ECMWF temperature and GPHs between 1000-10 hPa for the time interval May 2001 and December 2007.

We found a good agreement between the temperatures between $300-10 \mathrm{hPa}$ for all years/seasons with global annual mean biases (stddevs) of less than 0.3 (1.7) K. An observed positive global temperature bias trend $(300-10 \mathrm{hPa})$ between $2001(-0.2 \mathrm{~K})$ and $2006(0.3 \mathrm{~K})$ was clearly reduced to less 
than $0.1 \mathrm{~K}$ in 2007 after the assimilation of GPS RO data at ECMWF. The according temperature stddev in 2007 (1.5 K) was also reduced compared with the pre-assimilation period (between 1.6-1.7 K). The 'stratospheric ringing' observed in the temperature bias/stddev of the polar lower stratosphere disappeared after the assimilation of GPS RO data at ECMWF in December 2006.

Global annual mean biases (stddevs) of GPHs between $300-10 \mathrm{hPa}$ are in the range of -30 and $+5(30-50) \mathrm{gpm}$. The CHAMP-ECMWF GPH bias is more influenced by the increase of the ECMWF model levels from L60 to L91 than the assimilation of RO data.

Acknowledgements. The authors would like to thank all other members of the CHAMP team for their contributions to this study and the ECMWF for supplying the operational weather analyses. This work is funded through the research project 'IDEAL-GRACE' within the DFG priority program 1257 "Mass Transports and Mass Distribution in the Earth System".

Topical Editor F. D'Andrea thanks two anonymous referees for their help in evaluating this paper.

\section{References}

Anthes, R. A., Bernhardt, P. A., Chen, Y., et al.: The COSMIC/FORMOSAT-3 mission: Early results, B. Am. Meteorol. Soc., 89, 1-21, 2008.

Bormann, N. and Healy, S. B.: New observations in the ECMWF assimilation system: Satellite limb measurements, ECMWF Newsletter, 105, 13-17, 2005.

Borsche, M., Kirchengast, G., and Foelsche, U.: Tropical tropopause climatology as observed with radio occultation measurements from CHAMP compared to ECMWF and NCEP analyses, Geophys. Res. Lett., 34, L03702, doi:10.1029/2006GL027918, 2007.

European Centre for Medium-Range Weather Forecasts (ECMWF): IFS Documentation - Cy31r1 Part II-IV, Reading, UK, 2007a.

European Centre for Medium-Range Weather Forecasts (ECMWF): Changes to the operational forecasting system, ECMWF Newsletter, 110, p. 2, 2007b.

European Centre for Medium-Range Weather Forecasts (ECMWF): Changes to the operational forecasting system, ECMWF Newsletter, 106, p. 2, 2006.

Flechtner, F., Schmidt, R., and Meyer, U.: De-aliasing of shortterm atmospheric and oceanic mass variations for GRACE, in: Observation of the Earth System from Space, edited by: Flury, J., Rummel, R., Reigber, Ch., Rothacher, M., Boedecker, G., and Schreiber, U., Springer, 83-97, 2006.

Gobiet, A., Kirchengast, G., Manney, G. L., Borsche, M., Retscher, C., and Stiller, G.: Retrieval of temperature profiles from CHAMP for climate monitoring: intercomparison with Envisat MIPAS and GOMOS and different atmospheric analyses, Atmos. Chem. Phys., 7, 3519-3536, 2007, http://www.atmos-chem-phys.net/7/3519/2007/.

Gobiet, A., Foelsche, U., Steiner, A. K., Borsche, M., Kirchengast, G., and Wickert, J.: Climatological validation of stratospheric temperatures in ECMWF operational analyses with CHAMP radio occultation data, Geophys. Res. Lett., 32(12), L12806, doi:10.1029/2005GL022617, 2005.

Hajj, G. A., Ao, C. O., Iijima, B. A., Kuang, D., Kursinski, E. R., Mannucci, A. J., Meehan, T. K., Romans, L. J., de la Torre Juarez, M., and Yunck, T. P.: CHAMP and SAC-C atmospheric occultation results and intercomparisons, J. Geophys. Res., 109, D06109, doi:10.1029/2003JD003909, 2004.

Healy, S. B., Wickert, J., Michalak, G., Schmidt, T., and Beyerle, G.: Combined forecast impact of GRACE-A and CHAMP GPS radio occultation bending angle profiles, Atmos. Sci. Lett., 8, 4350, 2007.

Healy, S. B.: Operational assimilation of GPS radio occultation measurements at ECMWF, ECMWF Newsletter, 111, 6-11, 2007.

Jensen, A. S., Lohmann, M., Benzon, H. H., and Nielsen, A.: Full Spectrum inversion of radio occultation signals, Radio Sci., 38(3), 1040, doi:10.1029/2002RS002763, 2003.

König, R., Michalak, G., Neumayer, K. H., Schmidt, R., Zhu, S. Y., Meixner, H., and Reigber, C.: Recent developments in CHAMP orbit determination at GFZ, in: Earth Observation with CHAMP, edited by: Reigber, C., Lühr, H., Schwintzer, P., and Wickert, J., Springer, Berlin, ISBN 3-540-22804-7, 65-70, 2005.

Kursinski, E. R., Hajj, G. A., Hardy, K. R., Schofield, J. T., and Linfield, R.: Observing Earth's atmosphere with radio occultation measurements using the Global Positioning System, J. Geophys. Res., 102, 23 429-23 465, 1997.

Leroy, S. S.: Measurement of geopotential heights by GPS radio occultation, J. Geophys. Res., 102, 6971-6986, 1997.

Melbourne, W. G., Davis, E. S., Hajj, G. A., Hardy, K. R., Kursinski, E. R., Meehan, T. K., and Young, L. E.: The application of spaceborne GPS to atmospheric limb sounding and global change monitoring, JPL Publication, 94-18, Jet Propulsion Laboratory, Pasadena, California, 1994.

Rocken, C., Anthes, R. A., Exner, M., Hunt, D., Sokolovskiy, S., Ware, R., Gorbunov, M., Schreiner, W., Feng, D., Herman, B., Kuo, Y. H., and Zou, X.: Analysis and validation of GPS/MET data in the neutral atmosphere, J. Geophys. Res., 102(D25), 29 849-29 866, 1997.

Rodgers, C. D.: Inverse Methods for Atmospheric Sounding, Theory and Practice, World Scientific, Singapore, 2000.

Schmidt, T., Beyerle, G., Heise, S., Wickert, J., and Rothacher, M.: A climatology of multiple tropopauses derived from GPS radio occultations with CHAMP and SAC-C, Geophys. Res. Lett., 33, L04808, doi:10.1029/2005GL024600, 2006.

Schmidt, T., Heise, S., Wickert, J., Beyerle, G., and Reigber, C.: GPS radio occultation with CHAMP and SAC-C: global monitoring of thermal tropopause parameters, Atmos. Chem. Phys., 5, 1473-1488, 2005a, http://www.atmos-chem-phys.net/5/1473/2005/.

Schmidt, T., Wickert, J., Beyerle, G., König, R., Galas, R., and Reigber, C.: The CHAMP atmospheric processing system for radio occultation measurements, in: Earth Observation with CHAMP, edited by: Reigber, C., Lühr, H., Schwintzer, P., and Wickert, J., Springer, Berlin, ISBN 3-540-22804-7, 597-602, 2005 b.

Schmidt, T., Wickert, J., Beyerle, G., and Reigber, C.: Tropical tropopause parameters derived from GPS radio occultation measurements with CHAMP, J. Geophys. Res., 109, D13105, doi:10.1029/2004JD004566, 2004. 
Smith, E. and Weintraub, S.: The constants in the equation for atmospheric refractive index at 20 radio frequencies, Proc. I.R.E., 41, 1035-1037, 1953.

Steiner, A. K., Kirchengast, G., Borsche, M., Foelsche, U., and Schoenengassner, T.: A multi-year comparison of lower stratospheric temperatures from CHAMP radio occultation data with MSU/AMSU records, J. Geophys. Res., 112, D22110, doi:10.1029/2006JD008283, 2007.

Tapley, B. D., Bettadpur, S., Ries, J. C., Thompson, P. F., and Watkins, M. M.: GRACE measurements of mass variability in the Earth system, Science, 305, 503-505, 2004.

Wang, D. Y., Stiller, G. P., von Clarmann, T., et al.: Crossvalidation of MIPAS/ENVISAT and GPS-RO/CHAMP temperature profiles, J. Geophys. Res., 109, D19311, doi:10.1029/2004JD004963, 2004.

Wickert, J., Beyerle, G., König, R., Heise, S., Grunwaldt, L., Michalak, G., Reigber, C., and Schmidt, T.: GPS radio occultation with CHAMP and GRACE: A first look at a new and promising satellite configuration for global atmospheric sounding, Ann. Geophys., 23, 653-658, 2005,

http://www.ann-geophys.net/23/653/2005/.
Wickert, J.: Comparison of vertical refractivity and temperature profiles from CHAMP with radiosonde measurements, Scientifical Technical Report GFZ Potsdam, STR 04/19, ISSN 16100956, www.gfz-potsdam.de/bib/pub/str0419/0419.pdf, 2004a.

Wickert, J., Schmidt, T., Beyerle, G., König, R., Reigber, C., and Jakowski, N.: The radio occultation experiment aboard CHAMP: Operational data analysis and validation of atmospheric profiles, J. Meteorol. Soc. Japan, 82(1B), 381-395, 2004b.

Wickert, J., Reigber, C., Beyerle, G., König, R., Marquardt, C., Schmidt, T., Grunwaldt, L., Galas, R., Meehan, T. K., Melbourne, W. G., and Hocke, K.: Atmosphere sounding by GPS radio occultation: First results from CHAMP, Geophys. Res. Lett., 28, 3263-3266, 2001. 